\title{
Adjective-noun order in Papiamento-Dutch code-switching
}

\author{
Leticia Pablos, ${ }^{1,2}$ M. Carmen Parafita Couto, ${ }^{1,2}$ \\ Bastien Boutonnet, ${ }^{1}$ Amy de Jong, ${ }^{1}$ Marlou Perquin, ${ }^{3}$ \\ Annelies de $\mathrm{Haan}^{3}$ and Niels O. Schiller ${ }^{1,2}$ \\ ${ }^{1}$ Leiden University Center for Linguistics / ${ }^{2}$ Leiden Institute for Brain and \\ Cognition $/{ }^{3}$ Cardiff University
}

In Papiamento-Dutch bilingual speech, the nominal construction is a potential 'conflict site' if there is an adjective from one language and a noun from the other. Adjective position is pre-nominal in Dutch (cf. rode wijn 'red wine') but post-nominal in Papiamento (cf. biña kòrá 'wine red'). We test predictions concerning the mechanisms underpinning word order in noun-adjective switches derived from three accounts: (i) the adjective determines word order (Cantone \& MacSwan, 2009), (ii) the matrix language determines word order (Myers-Scotton, 1993, 2002), and (iii) either order is possible (Di Sciullo, 2014). An analysis of spontaneous Papiamento-Dutch code-switching production (Parafita Couto \& Gullberg, 2017) could not distinguish between these predictions. We used event-related brain potentials (ERPs) to measure online comprehension of code-switched utterances. We discuss how our results inform the three theoretical accounts and we relate them to syntactic coactivation and the production-comprehension link.

Keywords: code-switching, conflict sites, nominal constructions, Papiamento, Dutch, event-related potentials

\section{Introduction}

In many communities, it is common for multilinguals to use elements from multiple languages within a single conversation - a phenomenon known as code-switching. The focus of this study is on the way languages "work together" at grammatical 'conflict sites' (area(s) in which the structures of the two languages differ), in particular adjective-noun switches when adjectives are pre-nominal in 
one of the languages and post-nominal in the other language. For example, adjective position is pre-nominal in Dutch (cf. rode wijn 'red wine') but post-nominal in Papiamento (cf. biña kòrá 'wine red'). Hence, code-switching between Papiamento and Dutch could potentially yield four different logical outcomes: 'rode biña', 'biña rode, 'kòrá wijn' and 'wijn kòrá.

Theories of the regularities governing these conflict sites are still in need of better understanding. As we explain in Section 2, there seems to be an impasse in code-switching research, with contradictory evidence for the different theoretical positions. This may be the case because of the methodologies used. While bilingual corpora and elicited data provide examples of what type of code-switches can occur, acceptability judgments provide information about comprehension and exposure to a range of constructions. However, due to the often stigmatized nature of code-switching, acceptability judgment tasks are not always useful (Parafita Couto, Deuchar, \& Fusser, 2015a; Stadthagen-González, López, Parafita Couto, \& Párraga, 2018). It may be advantageous, then, to adopt techniques which measure more automatic reactions. However, there is a scarcity of psycholinguistic studies that focus on switching between languages within the sentence, where both semantic and syntactic information must be integrated (see Gullberg, Indefrey, \& Muysken, 2009; Guzzardo Tamargo, Valdés Kroff, \& Dussias, 2016; Parafita Couto, Boutonnet, Hoshino, Davies, Deuchar, \& Thierry, 2017; Van Hell, Fernández, Koostra, Litcotsky, \& Ting, 2018; Valdés Kroff, Guzzardo Tamargo, \& Dussias, 2018).

This is precisely what we set out to do in this paper, building on previous work by Parafita Couto and Gullberg (2017) who approached the evaluation of two theoretical accounts (i.e., the Matrix Language Framework (MLF, Myers-Scotton, 1993) and a Minimalist Program approach (MP, Cantone \& MacSwan, 2009)) by examining patterns of adjective-noun switching produced by Papiamento-Dutch bilinguals in naturalistic speech. Due to the low number of switches between the adjective and the noun in naturalistic speech, their results were inconclusive. To see whether neurocognitive methods can inform linguistic theory, in this study we look for the neural correlates underlying the comprehension of adjective-noun switches in Papiamento-Dutch bilingual speech.

According to proponents of the MLF, the grammar of one of the two languages takes priority. A distinction is made between the 'matrix language' (ML) and the 'embedded language' (EL). The MLF model predicts that (1) finite verb morphology and (2) word order within a clause that contains code-switching will all be sourced from the same language (the ML). If the bound morphology of the finite verb is from Language $A$, then it is predicted that the word order of an adjective and noun in a noun phrase containing code-switching in the same clause will also be from Language A. Following the general prediction outlined above, the 
MLF predicts that the noun/adjective order in a mixed (code-switched) nominal construction will match the language of the finite verb morphology, i.e., the $\mathrm{ML}$ (Myers-Scotton, 1993, 2002).

In contrast, those who support the MP resort to the constraints governing the individual lexical items (MacSwan, 2002). MacSwan (1999) has criticized the MLF - arguing that the grammatical principles responsible for defining the distribution of code-switching explicitly refer to the separate languages involved in it. Regarding adjective order, Cantone and MacSwan (2009) follow Cinque's (1994, 1999, 2005) proposal that a Universal Base underlies adjectives, with adjectives universally preceding the noun. Cantone and MacSwan explore Italian-German naturalistic code-switching data and reach the descriptive generalization that "while the data remain slightly ambiguous, a relatively clear pattern has emerged in both the survey data and the naturalistic data confirming the general view of previous researchers, namely, that the word order requirements of the language of the adjective determine word order in code-switching in DP-internal contexts" (2009, pp. 266-267).

An earlier proposal by Santorini and Mahootian (1995) and Mahootian and Santorini (1996) postulated that all combinations of adjectives and nouns are possible because only heads determine the position of their complements, and adjectives are nominal adjuncts. This proposal was disputed in the literature, but recently DiSciullo (2014) argued along similar lines that code-switching is possible in modification sites. She assumes that adverbial and adjectival modifiers occupy the specifier position of a functional (F) category asymmetrically ccommanding the lexical projections it modifies. Code-switching is predicted to be possible in these sites, as code-switching may occur at the juncture of an Adjective and a Noun, since Adjectives are generated by External Merge in the specifier of a functional category.

\section{Evaluation of theoretical models}

There have been attempts to explain code-switching at conflict sites, but none of the approaches to date are exhaustive - a bleak conclusion put forward by Moro (2015). The studies so far, conducted in different language pairs and using different methodologies, have yielded conflicting results. Parafita Couto et al. (2015a, p. 66) argue that these inconclusive results may be due to the fact that research on conflict sites in code-switching has not been approached from a multidisciplinary perspective. To this end, Parafita Couto et al. (2015a) designed a study to evaluate the predictions of the models at conflict sites (adjective and noun) within Welsh-English mixed nominal constructions by using a multitask 
approach comprising: (i) naturalistic corpus data, (ii) an elicitation task, and (iii) an auditory judgment task. They found that judgment tasks are not very useful in this community of code-switchers, due to the stigma associated with the phenomenon (see also Badiola, Delgado, Sande, \& Stefanich, 2018 for a recent discussion of the role of attitudes on code-switching judgment tasks). However, the data from the naturalistic corpus and the elicitation task were compatible with one another, yielding support for the relative superiority of the MLF model. Nevertheless, only a small proportion of their data could distinguish between the models. Parafita Couto et al. (2015a) suggest that due to the often stigmatized nature of code-switching, it may be useful to adopt techniques less prone to the influence of strategic judgments, and that neuroscientific evidence seems particularly well suited to the study of intra-sentential code-switching since it allows to examine the automatic processes that occur prior to conscious judgments. However, the vast majority of ERP studies examining switching between languages has focused on the processing of single items rather than switching between different items within the sentence level (at a conflict site), where both semantic and syntactic information need to be integrated (see Van Hell, Litcofsky, \& Ting, 2015, for a review). To our knowledge, the only neuroscientific work on conflict sites within the nominal construction is the study by Parafita Couto, Boutonnet, Hoshino, Davies, Deuchar, and Thierry (2017) on Welsh-English code-switching, aimed at complementing Parafita Couto et al.s (2015a) study of adjective-noun switching, which yielded inconclusive results due to the inherent limitations of corpora of naturalistic production data. Hence, Parafita Couto et al. (2017) designed an electrophysiological study to look at Welsh-English conflict sites within the noun phrase aimed at testing the predictions of the Myers-Scotton's MLF approach and Cantone and MacSwan's approach with the Minimalist Program (MP). Adjective position is strictly pre-nominal in English (e.g., red book), however, it is strictly post-nominal in Welsh (e.g., llyfr coch 'book red'). Parafita Couto et al. investigated the acceptability of code-switched nominal constructions using a sentence verification task and ERPs. They manipulated (i) the morphosyntactic frame of the sentence verb (which always preceded the code-switches), (ii) the language of the adjective, (iii) the language of the noun, and (iv) word order. The predictions for Welsh-English code-switching were as follows: whereas the MLF predicted that a Welsh adjective in pre-nominal position within a sentence with an English matrix language would be acceptable, it predicted a violation for English adjectives in pre-nominal position within a sentence with a Welsh matrix language. Critically, predictions from Cantone and MacSwan's account within the MP, solely based on the language of the adjective, were exactly the opposite (see Table 1 for a set of their stimuli and their predictions). 
Table 1. Characteristics of materials and associated predictions for the Welsh-English study by Parafita Couto et al. (2017). The + sign stands for a correct sentence and the sign stands for a violation. The adjective in which measures were taken appears in bold.

\begin{tabular}{|c|c|c|c|}
\hline & Matrix language & MLF prediction & MP prediction \\
\hline $\begin{array}{l}\text { A. The bear chased one ceffyl white. } \\
\text { 'the bear chased one [horse white]' }\end{array}$ & English & - & - \\
\hline $\begin{array}{l}\text { B. The bear chased one gwyn horse. } \\
\text { 'the bear chased one [white horse]' }\end{array}$ & English & + & - \\
\hline $\begin{array}{l}\text { C. Helodd yr arth un horse gwyn. } \\
\text { 'the bear chased one [horse white]' }\end{array}$ & Welsh & + & + \\
\hline $\begin{array}{l}\text { D. Helodd yr arth un white ceffyl. } \\
\text { 'the bear chased one [white horse]' }\end{array}$ & Welsh & - & + \\
\hline $\begin{array}{l}\text { E. The bear chased one white horse. } \\
\text { 'the bear chased one [white horse]' }\end{array}$ & English & No switch & No switch \\
\hline $\begin{array}{l}\text { F. Helodd yr arth un ceffyl gwyn. } \\
\text { 'the bear chased one [horse white]' }\end{array}$ & Welsh & No switch & No switch \\
\hline
\end{tabular}

Parafita Couto et al. (2017) found a negative-going ERP waveform corresponding to a left anterior negativity (LAN), an ERP component which signals syntactic violations such as phrase structure or morphosyntactic violations (e.g., Friederici, 2002; Friederici, Pfeifer, \& Hahne, 1993; Hagoort, 2003; Hahne \& Friederici, 1999). The LAN that Parafita and colleagues found had a maxima over frontal regions of the scalp in the time-window between $280-340 \mathrm{~ms}$ in the condition predicted by the MLF to induce a violation ( $D$ with respect to $B$ ), supporting the MLF account. A direct comparison between ERPs elicited by Welsh and English adjectives in monolingual non-code-switched sentences (i.e., E and F) showed no significant difference in the same time-window. However, a comparison between the conditions in which both models predicted the same outcome (i.e., A and C) yielded no significant effect. Thus, Parafita Couto et al. argued that the MLF offers a better account of the Welsh-English data than Cantone and MacSwan's account, without conclusive results.

These results leave lots of unanswered questions regarding the mechanisms underpinning intra-sentential code-switching in conflict-sites: How generalizable are the code-switching constraints posited by the theoretical models? Can these results be found in a different language pair with a similar word order conflict? In the current study, we test the predictions of these models regarding noun-adjective order in Papiamento-Dutch code-switched utterances. Since in Papiamento-Dutch code-switching there is a similar conflict in the order of the elements within the noun phrase (i.e., adjectives appear in pre-nominal position in Dutch and in postnominal position in Papiamento, cf. Section 3), this language pair provides an 
ideal scenario for testing further the predictions made by the two code-switching theories examined in the Welsh-English study. We also test the possibility that either word order may be possible in modification sites (Di Sciullo, 2014).

\section{Adjective-noun switches in Papiamento-Dutch}

Dutch (a Germanic language) and Papiamento (an Iberian-based Creole) are spoken on the islands of Aruba, Bonaire and Curaçao in the Caribbean, and by some immigrant populations in the Netherlands. Around 100.000 Antillean immigrants reside in the Netherlands, most of whom speak Papiamento at home (Jacobs \& Muysken, in press). Papiamento is the sixth most frequently spoken heritage language in the Netherlands, following Turkish, Arabic, Berber, English, and Hind(ustan)i (Extra, Aarts, van der Avoird, Broeder, \& Yagmur, 2002; Extra, 2013). It is well known that Papiamento-Dutch bilinguals 'mix' their languages in the same sentence when they communicate with one another (Gullberg \& Parafita Couto, 2016).

In Papiamento adjective-noun ordering, the majority of attributive adjectives follow the nouns that they modify, as shown in (1). ${ }^{1}$ In contrast, attributive adjectives in Dutch occur before the noun that they modify (Broekhuis, 2013), as in (2).

(1) biña kòrá

wine red

'red wine'

Papiamento

(2) rode wijn

'red wine'

Dutch

In Papiamento-Dutch bilingual speech, the nominal construction may be the stage of a potential conflict site. Hence, we investigate what happens when an adjective from one language is combined with a noun from the other.

Cantone and MacSwan (2009) argue that the language of the adjective determines word order, predicting wijn kòrá and rode biña, and excluding biña

1. Although adjectives normally appear in postnominal position in Papiamento, some adjectives can appear in prenominal position as well (cf. Goilo, 1972, p. 47; Kouwenberg \& Murray, 1994, p. 48; Kouwenberg, 2007, p. 324; Munteanu, 1996, p. 287). A handful of adjectives can be either prenominal or postnominal without change of meaning (dushi 'sweet', bunita 'beatiful, fine', bon 'good'), while other prenominal modifiers are either quantifiers (e.g. delaster 'last', henter 'whole', algun 'some', etc.), numerals and ordinals, or belong to a small class of adjectives which have an affective interpretation in the prenominal position (see http://apics-online.info/contributions/47). Our study only included adjectives that normally appear in postnominal position. 
rode or kòrá wijn. Following Myers-Scotton (2002), by contrast, the word order is expected to follow that of the morphosyntax in the rest of the sentence, predicting wijn kòrá and biña rode when the morphosyntax of the rest of the sentence is in Papiamento, but rode biña and kòrá wijn when the rest of the sentence is in Dutch.

It is also relevant for our study to note that while Papiamento does not mark gender, Dutch differentiates between common gender (nouns that are preceded by the Dutch article $d e$ ), and neuter gender (nouns that are preceded by the Dutch article het; see Schiller \& Caramazza, 2003; Schriefers, 1993). Attributive adjectives are inflected with a schwa in all cases except with singular, indefinite neuter nouns. This special status of the neuter gender in indefinite nominal constructions is accompanied by an asymmetrical distribution of the two gender categories: the common gender comprises around 75\% of all Dutch nouns (Van Berkum, 1996). Because of the scarce evidence in the input, children tend to overgeneralize the common determiner 'de' until around the age of 6 (Blom, Polisenskà, \& Weerman, 2008). In addition, the overt spell-out $-e$ in attributive adjectives is overgeneralized and therefore appears to be the default in Dutch (Orgassa, 2009).

\subsection{Adjective-noun switches in Papiamento-Dutch bilingual production}

Papiamento-Dutch code-switching in the Netherlands has previously been studied in bilingual parent-child reading situations looking at language choice and functional differentiation between the languages (cf. Muysken et al., 1996). The only previous study that has examined code-switching in adult interaction is based on corpus data (Parafita Couto \& Gullberg, 2017). Relevant for our present research, results of this corpus study showed that the most common switching pattern is the following: determiners in Papiamento followed by adjectives and nouns in Dutch (what the MLF calls 'islands'), as in (3).

(3) e simpele voetganger

Det simple pedestrian

'The simple pedestrian'

This means that adjectives appear in the position of Dutch grammar. There are, however, only eight cases in the corpus of switches between the adjective and the noun, which are not enough to reach any solid conclusion regarding what determines adjective position in code-switching (see Table 5 and appendix in Parafita Couto \& Gullberg, 2017). Two of these cases include the type of adjectives that can be prenominal in Papiamento followed by a Dutch noun, thus not allowing us to disambiguate between the different proposals. Three cases include a Dutch noun insertion in an otherwise Papiamento utterance. These examples are predicted to be grammatical by all three theoretical proposals. There are only three examples 
that allow us to arbitrate between the theoretical approaches - they include a Dutch adjective in postnominal position. Since the matrix language in all clauses in this corpus is Papiamento, these examples align with the MLF predictions. However, all three examples have long pauses between the noun and the adjective, which may signal a disfluency, and thus, they cannot be interpreted as reliable support for the MLF predictions.

As pointed out earlier, the fact that these switches are rare in the corpus does not mean that they are impossible or accidental (López, 2017; Parafita Couto et al., 2014). As argued by López (2017), bilinguals are not different from monolinguals as a single linguistic competence grows out of the faculty of language. The challenge, however, is to be able to tap into the linguistic competence of bilinguals, particularly when the phenomenon under study is socially stigmatized. Techniques such as ERPs that measure automatic reactions may be helpful in this respect.

3.2 Towards the present study: Adjective-noun switches in PapiamentoDutch bilingual comprehension

In this study, we embarked on an ERP comprehension experiment in which we tested whether the less frequent switch in the production data between the noun and the adjective could provide us with some hints as to how Papiamento-Dutch code-switchers behave with respect to the predictions put forward by the different theoretical accounts.

\subsubsection{Predictions for the present ERP study on Papiamento-Dutch}

Syntactic violations can be flagged by the ERP component LAN (e.g., Friederici, 2002; Friederici, Pfeifer, \& Hahne, 1993; Hagoort, 2003; Hahne \& Friederici, 1999). Prior similar research on Welsh-English code-switchers processing conflict-sites within the nominal construction also found a LAN in the condition predicted by the MLF to induce a violation (cf. Section 2). Since the adjective-noun conflict in our study consisted of a (potential) syntactic violation for Papiamento-Dutch code-switchers, we predicted that at least an anterior negativity would occur when the correct prediction by each theory (Cantone \& MacSwan, 2009 vs. MyersScotton, 2002) is violated. If, on the other hand, code-switching at modification sites is always allowed (following Di Sciullo, 2014), we should not observe any differences between conditions. 


\section{Materials and methods}

\subsection{Participants}

Eighteen highly proficient Papiamento-Dutch bilinguals (13 females, 5 males; $M_{\text {age }}=24$ ) took part in the experiment. ${ }^{2}$ Almost all of the participants grew up in Curaçao, Aruba, or Sint Maarten and moved to the Netherlands for their university studies, which they carry out in Dutch. All had normal, or corrected to normal, vision.

A questionnaire (adapted from Parafita Couto, Munarriz, Epelde, Deuchar, \& Oyharçabal, 2015b) was given to the participants to obtain more information about their language background. Participants had a choice to fill in the questionnaire in either Dutch or Papiamento. It included questions about: (i) self-reported proficiency in both Papiamento and Dutch, (ii) information on where participants had lived previously, (iii) what languages they were using on a daily basis with their parents, caregivers and closest social network, and (iv) their attitudes towards code-switching and towards mixing Dutch and Papiamento (see Table 2 for the information provided by participants in the questionnaire on age, proficiency, and language use with parents, caregivers, and closest social network).

Table 2. Information provided by participants on the questionnaire on age, self-reported proficiency and language usage with closest social network.

\begin{tabular}{lcc}
\hline Measure & Mean & SD \\
\hline Age & 23.6 & 9.1 \\
Papiamento proficiency (1-5 scale) & 3.8 & 0.3 \\
Dutch proficiency (1-5 scale) & 3.3 & 0.7 \\
Use of Papiamento (\%) & 46.6 & 28.3 \\
Use of Dutch (\%) & 26.7 & 24 \\
Use of both (\%) & 13.3 & 18.9 \\
Use of another language (\%) & 13.3 & 21.1 \\
\hline
\end{tabular}

The answers on the questions in the questionnaire connected to participants' attitudes towards code-switching in everyday conversation are shown in Figure 1.

Even though all participants report using both Dutch and Papiamento on a daily basis, as seen in Figure 1, not all of them report to habitually code-switch.

2. The total number of subjects participating in the experiment was 20 . However, the data from two participants was discarded due to technical problems during EEG recording, therefore these two subjects were also excluded from the offline questionnaire analysis. 
"I keep Dutch and Papiamento separate in everyday conversation"

"You should avoid mixing Papiamento and Dutch in the same conversation"

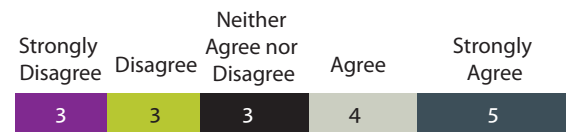

9

Figure 1. Questionnaire results on participants' attitudes towards code-switching (numbers reflect responses' counts in each category).

Attitudes towards code-switching are also mixed. This could be due to the usual stigma associated with the phenomenon (cf. Parafita Couto et al. 2015a).

The majority of the speakers were spoken to in Papiamento during their childhood. At the time of the study, eighty percent of the participants had lived in the Netherlands for five years or less.

The language of instruction in primary school was either solely Dutch (60\%) or a mixture of Dutch and Papiamento (40\%). Results from secondary education were similar, with $75 \%$ of participants taught in Dutch, and $25 \%$ taught in a mixture of Dutch and Papiamento. Most participants did not start to learn Dutch until they attended school around age 4 or 5 .

\subsection{Materials}

An experimental trial was defined as a sentence consisting of seven words (with $\mathrm{S}$ (ubject)-V(erb)-O(bject) structure) grouped in six different regions for presentation purposes presented in rapid serial visual presentation (RSVP) style which participants were requested to read while we recorded their brain activity. After each sentence was presented, participants were shown two pictures (left and right side) and they were asked to choose, by pressing a button on the button box, the picture that best depicted the situation portrayed in the sentence. This was done in order to ensure that they were paying attention to the sentences they read.

The materials for the experiment consisted of forty sets of six simple sentences (240 in total) that contained the following constituents: (i) a subject noun, (ii) a verb and (iii) an object noun. The object noun phrase consisted of an adjective following-or-preceding the noun. This is where the code-switch occurred. Every word within these constituents was presented in isolation except for the verb, which consisted of an auxiliary and a participle in Papiamento, and a verb in Dutch (except for 6 out of 40 items, in which the verb contained a preposition, e.g., joeg $o p$ 'to chase', and schoot op 'throw at'). The noun and the adjective were presented separately. We were particularly interested in the ERPs generated at the adjective position, which was our measuring point for the analysis (cf. Section 4.4). To avoid a lengthy experiment, no fillers were included. We considered that the monolingual control conditions could act as fillers of the code-switched conditions and 
we think that adding a high number of monolingual sentences in the experiment could affect the code-switching mode of the participants. No nouns or adjectives were cognates in Papiamento and Dutch.

Table 3 shows an example of one sentence set, containing the six different conditions, their corresponding matrix language, and whether or not they are compatible with the predictions of the MLF hypothesis and Cantone and MacSwan's MP approach. Each sentence set contained two control monolingual conditions (one in Dutch, one in Papiamento - sentence E and F, respectively) with grammatically correct word order. The remaining four conditions contained adjective-noun code-switches: two with Dutch as the morphosyntactic frame (sentences A and B), and two with Papiamento (sentences C and D). The codeswitched sentences had the adjective either before the noun (sentences $B$ and D) or after the noun (sentences A and C). Furthermore, two of the conditions made right predictions within the MLF (sentences $B$ and $C$ ) and two within the MP (sentences $C$ and D), which meant that both theories predicted sentence $C$ to be right and sentence A to be wrong. Even if the analysis was always carried out at the adjective position (as discussed in Section 4.4), it has to be noted that this position does not always correspond with the beginning of the code-switch. This was only the case for conditions B and D, which were compared with each other in the analysis.

Table 3. Characteristics of materials and associated predictions for Papiamento and Dutch. The + sign stands for a correct sentence and the - sign stands for a violation. The adjective in which measures were taken appears in bold.

\begin{tabular}{llll}
\hline & $\begin{array}{l}\text { Matrix } \\
\text { Language }\end{array}$ & $\begin{array}{l}\text { MLF } \\
\text { prediction }\end{array}$ & $\begin{array}{l}\text { MP } \\
\text { prediction }\end{array}$ \\
\hline $\begin{array}{l}\text { A. De zeehond volgde één kangreu kleine. } \\
\text { 'The seal followed a [crab small]' }\end{array}$ & Dutch & - & - \\
$\begin{array}{l}\text { B. De zeehond volgde één chikí krab. } \\
\text { 'The seal followed a [small crab]' }\end{array}$ & Dutch & + & - \\
$\begin{array}{l}\text { C. E foka a sigui un krab chikí. } \\
\text { 'The seal followed a [crab small]' }\end{array}$ & Papiamento & + & + \\
$\begin{array}{l}\text { D. E foka a sigui un kleine kangreu. } \\
\text { 'The seal followed a [small crab]' }\end{array}$ & Papiamento & - & + \\
$\begin{array}{l}\text { E. De zeehond volgde één kleine krab. } \\
\text { 'The seal followed a [small crab]' }\end{array}$ & Dutch & No switch & No switch \\
$\begin{array}{l}\text { F. } \text { E foka a siguí un kangreu chikí. } \\
\text { 'The seal followed a [crab small]' }\end{array}$ & Papiamento & No switch & No switch \\
\hline
\end{tabular}


Seventy-eight pictures were used for the verification of the sentence content. These pictures corresponded to the nominal constituents in the sentence (both subject and object) and were extracted from the Max-Planck Institute picture database (http://www.mpi.nl). In some cases, they were manipulated by changing their colour or size in order to fit the content of the sentence and to target the adjective in particular, which referred to either colour or size.

\subsection{Procedure}

The experiment followed the Ethics Code for linguistic research in the faculty of Humanities at Leiden University, which approved its implementation. The experiment took place in the Social Sciences Department at Leiden University, The Netherlands. First, participants were given an informed consent form to fill out along with a questionnaire about their language background, in a choice of either Dutch or Papiamento. The majority of the participants chose to fill it out in Dutch. This may reflect the fact that they received most of their education in Dutch, and, therefore, they are more comfortable with written Dutch than with written Papiamento.

Participants were tested individually, seated in front of a computer. They were instructed to first read sentences that were presented to them word by word on the screen in RSVP manner, and then to select the picture on the right or left that best matched the content of the sentence by pressing a button on the SR button box. First, they were given a small training of six sentences and were asked if they had any additional questions. Next, they were presented with six blocks, each comprising 40 sentences, with breaks in between the blocks. Each sentence was presented once during the experiment and only one condition per set was presented in each block. The sentences were randomized within each block. The experiment lasted approximately 40 minutes excluding setup time, which took an additional two hours approximately.

For each trial, a fixation cross was displayed for $1,000 \mathrm{~ms}$, followed by a blank screen of the same length. The sentences were presented word by word in the center of the screen. Each of the six regions used for stimuli presentation in the sentences was displayed for $200 \mathrm{~ms}$, and was followed by a blank screen for $500 \mathrm{~ms}$. Once the last word had been shown, an image to the left of the screen and one to the right were displayed and remained there until participants responded with a button press depending on which image most accurately fitted what they had just read. Only one of the pictures matched the preceding sentence in content. After their response, a blank screen of $500 \mathrm{~ms}$ preceded the fixation cross announcing the next trial. The response to the pictures ensured that participants would actually read the sentences and stay attentive throughout the entire experiment. 
The accuracy for the picture verification task was quite high across participants and conditions. The overall accuracy was $95 \%(S D=3 \%)$ and, for each condition, it was 98\% (A), 95\% (B), 94\% (C), 97\% (D), 94\% (F) and 91\% (E). Due to the high accuracy results, no data were excluded for the data analysis based on this information.

\subsubsection{Electrophysiological recording}

The EEG was continuously recorded at a rate of $512 \mathrm{~Hz}$ from $32 \mathrm{Ag} / \mathrm{AgC1}$ electrodes placed according to the extended 10-20 convention from a BioSemi (Active Two) system. Six additional electrodes were attached on the face of the participant to measure horizontal eye movements and eye blinks. Mastoids were used as the reference electrodes during acquisition. EEG data were referenced on-line to the CMS (Common Mode Sense) and DRL (Driven Right Leg) electrodes. Vertical and horizontal eye movements were recorded from two electrodes at the infraorbital and supraorbital regions and an electrode at the outer canthus of the right eye.

\subsection{Data analysis}

All EEG preprocessing and averaging steps were carried out in Brain Vision Analyzer (Brain Products $\mathrm{GmbH}$ ). Continuous EEG recordings were re-referenced offline to the mean of the activity at the two mastoids and were filtered using a zero-phase shift band-pass filter with a low cutoff of $0.1 \mathrm{~Hz}$ ( $24 \mathrm{~dB} /$ oct slope) and a high cutoff of $30 \mathrm{~Hz}$ ( $48 \mathrm{~dB}$ /oct slope). Eye-blink artefacts were corrected using an implementation of the Gratton, Coles, and Donchin (1983) algorithm (Brain Vision Analyzer). Epochs with activity exceeding $\pm 75 \mu \mathrm{V}$ at any electrode site were automatically discarded. EEG recordings were then segmented from -100 to $1,000 \mathrm{~ms}$ relative to stimulus onset. A baseline correction was applied using the $100 \mathrm{~ms}$ of pre-stimulus activity. Subsequently, ERPs were calculated by averaging the epochs time-locked to the stimulus of interest, i.e., the adjective position.

Following the main research question regarding the fit of the predictions made by the code-switching theories to the current data, initially four conditions were selected for comparisons: (i) B and D, and (ii) A and C. The first set of conditions compared sentence $\mathrm{B}$ and $\mathrm{D}$ at the pre-nominal adjective position. As discussed in Section 2, the proposals by Cantone and MacSwan (MP) and Myers-Scotton (MLF) make predictions that are mutually exclusive in this pair of conditions: in sentence $\mathrm{B}$, for example, the MP model predicts a violation while the MLF does not and viceversa. The second set of conditions compared sentences $\mathrm{A}$ and $\mathrm{C}$ at the post-nominal adjective position. The two models predicted a violation in $\mathrm{A}$ and no violation in C. Importantly, in both sets of conditions (B vs. D) and (A vs. C), the language of the adjectives differed ( $\mathrm{A}$ and $\mathrm{D}$ had Dutch kleine, while $\mathrm{B}$ and $\mathrm{C}$ 
had Papiamento chikí). We, therefore, carried out a control comparison of a third set of monolingual conditions in which the language of the adjectives also differed (E had Dutch kleine, F had Papiamento chikí) and where the adjectives occurred pre-nominally (E) and post-nominally (F), a comparison inherent to research on conflict sites (cf. Parafita Couto et al., 2017).

Taking into account our predictions in Section 4.1, we first analysed a specific time-window for the LAN, which is known to index the processing of a codeswitch (cf. Moreno, Ferdermeier, \& Kutas, 2002) and has been found in previous studies on conflict-sites (cf. Parafita Couto et al., 2017). For each participant, ERP mean amplitudes $(\mu \mathrm{V})$ as well as peak latencies (ms) were derived from and analysed in the time window 280-340 ms of an anterior region of the scalp composed of electrodes AF3, F3, F4, AF4, and Fz (5 total). The peak detection algorithm was set to return the latency (ms) of the lowest amplitude point $(\mu \mathrm{V})$ in the timewindow region of interest. Mean amplitudes and peak latencies were submitted to a repeated-measures ANOVA with Model Prediction as a within-subjects factor and amplitude or latency as a dependent variable (Schiller, Schuhmann, Neyndorff, \& Jansma, 2006).

One of the limitations of traditional ANOVA approaches as mentioned above is that ANOVAs cannot differentiate between the presence and the absence of evidence for the null hypothesis. In other words, once an effect fails to reach a given alpha level $(p<.05$ by convention), it is impossible to know whether this is due to a lack of statistical power or to the genuine absence of an effect. Bayesian statistics, however, can provide such information. We, thus, calculated Bayes Factors to investigate the mean amplitude and peak latency effects further. Bayes Factors (BFs) express the ratio of evidence in favour of one vs. another hypothesis. Therefore, it is possible, from a BF, to obtain information about the likelihood of the null or alternative hypothesis. By convention (Jeffreys, 1961), a $\mathrm{BF}>3$ provides moderate evidence for the alternate hypothesis, a $\mathrm{BF}>10$ signals strong evidence in favour of the alternate hypothesis and very strong evidence in favour of the alternate hypothesis is interpreted at ratios $>30$. Evidence in favour of the null hypothesis is moderate with a $\mathrm{BF}<1 / 3$, strong with a $\mathrm{BF}<1 / 10$, and very strong with a $\mathrm{BF}<1 / 30$. A $\mathrm{BF} \sim 1$ provides no evidence in favour of either hypotheses. BFs were obtained using the BayesFactor, R package (version 0.9.11-1; Morey \& Rouder, 2015).

In addition to the statistical tests described above, an exploratory whole scalp analysis was performed to evaluate the presence or absence of differences in the ERPs with different topographical contributions and at other latencies. Our interest was to investigate if other relevant components such as the late positive component (LPC) or the N400 could emerge. To that effect, we conducted a mass univariate analysis of the ERPs (Groppe, Urbach, \& Kutas, 2011; Maris \& 
Oostenveld, 2007). The ERPs from the compared conditions were submitted to a repeated measures, two-tailed cluster mass permutation test (Suckling, Overmeyer, Rabe-Hesketh, Taylor, \& Brammer, 1999) considering a family-wise alpha level of 0.05 . Time points in the region $50-800 \mathrm{~ms}$ and all 32 electrodes were used in the test. Electrodes within $4.20 \mathrm{~cm}$ of each other were considered spatial neighbours and adjacent time points were taken as temporal neighbours. Repeated measures t-tests were performed for each comparison using the original data and 2,500 random within-participant permutations of the data. For each permutation, all $\mathrm{t}$-scores corresponding to uncorrected p-values of 0.05 or less were formed into clusters. The sum of the $t$-scores in each cluster is the "mass" of that cluster and the most extreme cluster mass in each of the 2,501 sets of tests was recorded and used to estimate the distribution of the null hypothesis.

\section{Results}

Effects at the adjective position in sentences on which the models make opposite predictions (B vs. D: pre-nominal chikí vs. kleine):

The repeated-measures ANOVA on ERP mean amplitudes revealed no significant effect of Model Prediction $(F(1,17)=.56 ; p=.46$; Figure 2A). Peak-latencies also failed to reveal any significant differences between the sentences of interest $(F(1,17)=.02, p=.89)$. We observed moderate evidence in favour of the null hypothesis (mean amplitude: $\mathrm{BF}=1 / 3.2$; peak latency: $\mathrm{BF}=1 / 4$ ) indicating no differences between the ERPs elicited by the adjectives in either $\mathrm{B}$ or $\mathrm{D}$.

Effects at the adjective position in sentences on which the models make similar predictions (A vs. C: post-nominal kleine vs. chikí):

The ANOVA carried out on ERP mean amplitudes revealed no significant effect of Model Prediction $(F(1,17)=.4, p=.53$; Figure $2 \mathrm{~B})$. Peak-latencies were also unaffected by this factor $(F(1,17)=.22, p=.64)$. We observed moderate evidence in favour of the null hypothesis (mean amplitude: $\mathrm{BF}=1 / 3.4$; peak latency: $\mathrm{BF}=1 / 3.8$ ).

Monolingual no-switched language control sentences (E vs. F: pre-nominal kleine vs. post-nominal chikí):

There was no significant difference between amplitudes elicited by Papiamento vs. Dutch adjectives $(F(1,17)=3.58, p=.07$; Figure $2 \mathrm{C})$. Peak latency was not modulated by adjective language either $(F(1,17)=1.53, p=.23)$. The Bayes Factors obtained in this comparison (mean amplitude: $\mathrm{BF}=1.04$; peak latency: $\mathrm{BF}=1 / 2.1$ ) did not provide evidence in favour of either hypothesis. 


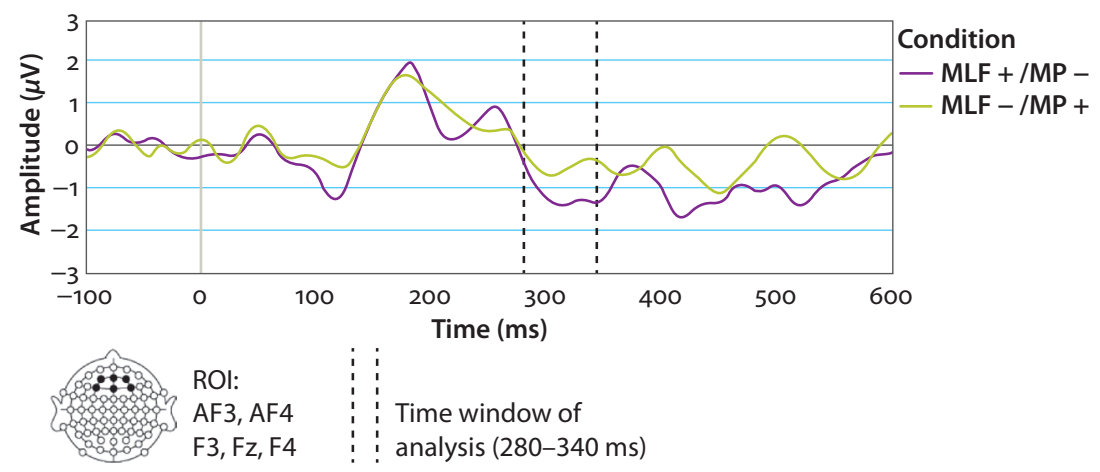

A. Sentences for which both models make orthogonal predictions (B vs. D)

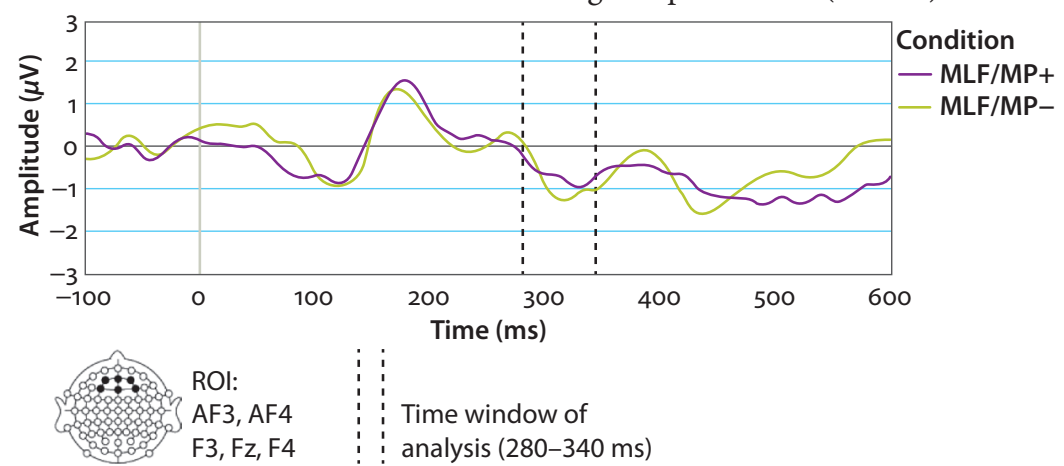

B. Sentences for which both models make parallel predictions (A vs. C)
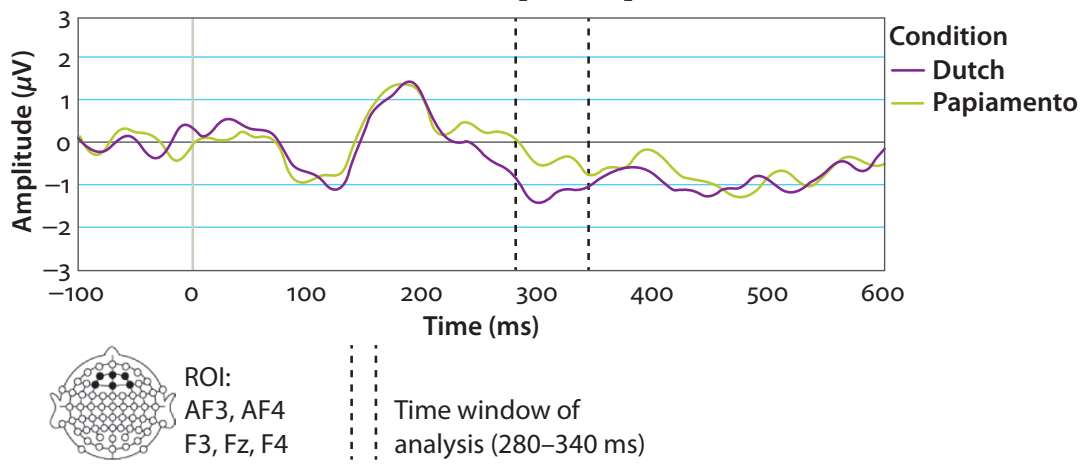

C. No effect of language on adjective processing

Figure 2. Event-related brain potentials elicited by (A) the adjective chikí (purple line) vs. kleine (green line) in penultimate position on which the models make orthogonal predictions, (B) the adjective kleine (green line) vs. chikí (purple line) in final position on which both models make identical predictions and (C) the Dutch and Papiamento control adjectives kleine (purple line) vs. chikí (green line) in penultimate position. The figure shows the average of 5 electrodes (AF3, F3, F4, AF4, and Fz) in the region of interest for the (A), (B) and (C) comparisons. 
The follow-up mass univariate analysis of the monolingual no-switched language control sentences $(E v s . F)$ did not reveal any significant cluster where the ERPs differed $(\alpha=0.05)$ at any time point/window analysed (all p-values $\geq 0.27$ ), as expected.

The comparison of sentences on which the models make similar predictions (A vs. C: kleine vs. chikí) did not produce any significant difference (p-values $\geq$ 0.09).

In sentences where models make opposite predictions ( $B$ vs. D: chikí vs. kleine), one cluster in the parietal-occipital electrodes, in the time window 275-350 ms showed a significant difference between ERPs $(p=0.04)$ as displayed in the raster plot in Figure 3. The plot shows a number of clusters where condition D was significantly more positive than condition $\mathrm{B}$, which meant that the condition predicted by the MLF to induce a violation resulted in a positive going ERP. Even if an effect in the condition predicted by the MLF to introduce a violation is also observed in the Welsh-English study by Parafita Couto et al. (2017) in that they found a LAN, the nature of our observed topographical distribution (i.e., occipital rather than frontal), its timing and polarity, cannot be related to a LAN. The topography and latency of the ERP effect in our study points instead to a component of the P300 type. The P300 effects occur in response to oddball paradigms in which frequently occurring stimuli (either tones or shapes) are interspersed with deviant stimuli. The response to deviant stimuli evokes a P300 and the effect is larger for taskrelevant, informative, salient, and improbable stimuli (Bornkessel-Schlesewsky \& Schlesewsky, 2009; Polich, 2004). To be more precise, due to its parietal scalp distribution, the effect that emerges from the comparison of $B$ vs. D resembles the subcomponent P3b (Polich, 2004, 2007). The P3b has been proposed "to originate from temporal-parietal activity associated with attention and appears to be related to subsequent memory processing and storage" (Polich, 2007, p. 2128). The P300 has been usually associated with non-syntactic manipulations of saliency, probability of occurrence, and task relevance, but not necessarily with syntactic violation manipulations (the reader is referred to the longstanding debate of whether the P3b and the P600 are part of the same "P300 family" in Bornkessel-Schlesewsky \& Schlesewsky, 2009 and Swaab, Ledoux, Camblin, \& Boudewyn et al., 2012). Even if this has been assumed in the ERP literature on the P300 component, the P3b effect in the above comparison (B vs. D) seems to point to an effect of attention or improbable/salient stimuli that might be generated by the syntactic violation investigated in our study. 


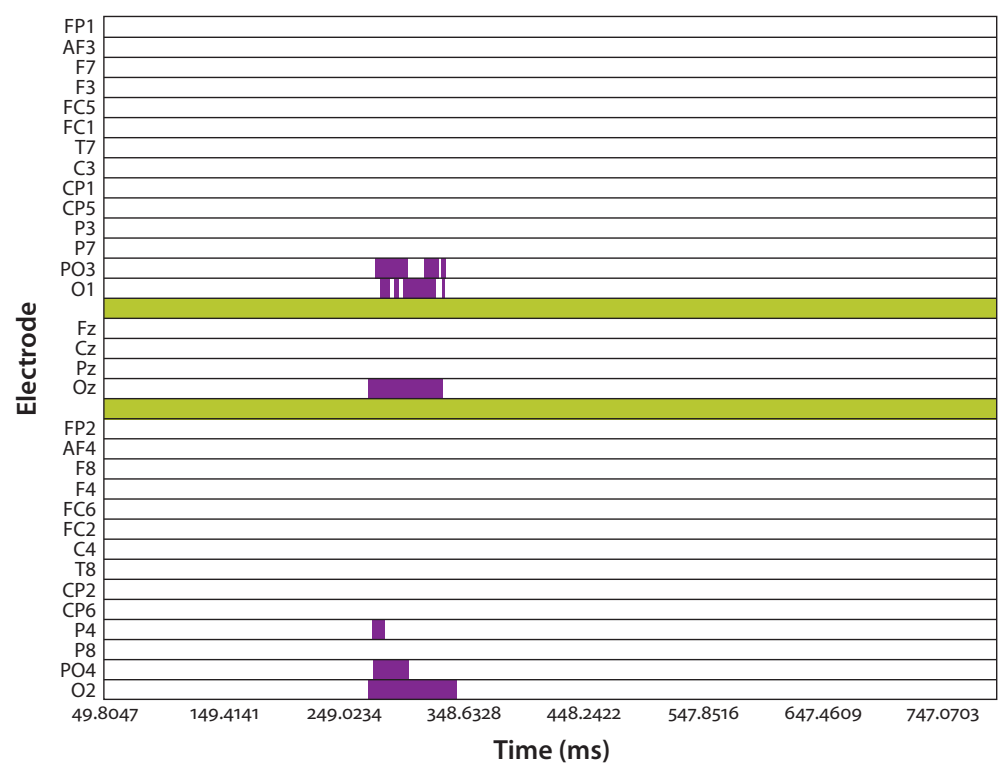

Figure 3. Raster plot displaying significant clusters ( $p$-value $<0.05)$ found in mass univariate analysis of the Event-related brain potentials elicited by the adjective in penultimate position on which the models make orthogonal predictions (Conditions B and D).

In summary, except in sentences where models make opposite predictions (B vs. D), in which one cluster in the parieto-occipital electrodes in the $275-350 \mathrm{~ms}$ time window showed a significant difference, no significant difference could be found in the analysis of the other two conducted comparisons for other latencies, nor in other particular locations.

\section{Discussion}

We experimentally investigated the contrasting predictions of Myers-Scotton (2002), Cantone and MacSwan (2009) and Di Sciullo (2014) regarding the mechanisms underpinning adjective placement in code-switching at a conflict site. Our experimental results do not lend support for Myers-Scotton (2002) nor Cantone and MacSwan (2009). Regarding Di Sciullo's (2014) proposal that code-switching is predicted to be possible in these sites, our results open the floor for further research, since the lack of difference between conditions could also mean that both sentences are unacceptable. In fact, if such switches are unacceptable, this would explain previous findings based on Papiamento-Dutch naturalistic production, which show that switching between a noun and an adjective is not common (Parafita Couto \& Gullberg, 2017). This may also explain the presence of the P300 
effect (i.e., an effect of attention or improbable stimuli). More empirical evidence, both from production and comprehension, and from different code-switching communities, would be needed to disentangle these theoretical possibilities.

We could possibly attribute our results to syntactic coactivation. Sanoudaki and Thierry (2014) found evidence of syntactic coactivation precisely in the nominal domain and argued that "bilinguals are open to grammatical switches as a result of language coactivation" (p. 229). Welsh-English bilinguals were better able to anticipate an adjective in post-nominal position in English than their English monolingual peers, possibly because their grammatical system allows for both $\mathrm{N}+$ Adj and Adj+N. It is possible, then, that what we observed in our experiment is simply due to coactivation. If that were the case, we should expect similar results if we tested the Papiamento-Dutch bilinguals in Dutch, but following the typical $\mathrm{N}+$ Adj order of Papiamento. This would be interesting for research modelling bilingual hybrid outputs, along the lines of Goldrick, Putnam and Schwartz (2016), who recently argued that simultaneously activated bilingual grammars can result in a variety of outputs.

Another avenue for future research would be to test Papiamento-Dutch bilinguals in a different community (for example, in the Antilles, where Papiamento is more dominant than in the Netherlands). Valdés Kroff (2016) argues that codeswitching is a learned behaviour and that different code-switching patterns may be learned in different communities of code-switchers. Consequently, whether bilinguals have immersed themselves in such a community, i.e., the bilingual profile in terms of usage and exposure to code-switching, should result in observable group differences in the production and comprehension of code-switching. Similarly, community differences in the preferred pattern of use in code-switching can and should arise because the specific structure that a community adopts may be influenced by a host of linguistic and extra-linguistic variables. Valdés Kroff (2016) found that Spanish-English bilinguals in Miami use predominantly masculine gender in mixed nominal constructions, and recent research indicates that Spanish-Basque code-switching has settled on the use of feminine-marked mixed nominal constructions as the dominant pattern (Parafita Couto et al., 2015b). Subsequently, Valdés Kroff (2016) argues that the predictions for online processing of gender should be different between Spanish-Basque and Spanish-English bilinguals. Valdés Kroff, Dussias, Gerfen, Perrotti, and Bajo (2017) also argued that bilinguals who are exposed to and engage in code-switching exploit distributional patterns present in speech production during comprehension. Even though this is an area for further research, if this claim can be confirmed with further studies, it would mean that we should not necessarily expect the Papiamento-Dutch bilingual community in the Netherlands to process adjective-noun switches in the 
same way as the Papiamento-Dutch bilingual community in the Antilles, where Papiamento is more present, but Dutch is less present.

We believe that the only way to further understand code-switching and the nature of the relation between frequency of production in naturalistic speech on the one hand, and processing on the other, would be to continue to collect multiple types of data from a variety of bilingual populations (see Gullberg et al., 2009). Åfarli, Grimstad and Subbarao (2013) draw attention to three broad types of contact situations: (i) immigrant community mixing (where a group of people from one language community settles on the native soil of another larger community), (ii) colonial influx mixing (where the language of a minority colonial master influences the majority native language of the colonized people), and (iii) balanced bilingual mixing (where the children master at least two languages more or less fluently and mix those two languages in their utterances). We could characterize Papiamento-Dutch contact as both (i) and (ii), depending on whether we are referring to the Antillean language contact situation or the contact situation in the Netherlands. It is possible, as Åfarli et al. (2013) point out, that each situation is unique, exhibiting its own particular features, which would lead to different switching types. If that is the case, then our grammatical and processing models should accommodate the outcomes of the different types of contact situations (Ålfarli et al., 2013; Kootstra, 2015; Muysken, 2013; Valdés Kroff, 2016). The (future) evaluation of similar studies may help showing which methodologies are most effective as well as provide valuable insight into the inner workings of the bilingual brain, which in turn can shed light on how to interpret the results from studies like this one.

The next steps should be to build a stronger overall evidence base so that we can tackle the question of whether or not neurological findings can arbitrate between the different theoretical proposals. Some methodological confounds compromise our ability to fully understand the cognitive underpinning of codeswitching at conflict sites. For example, in our study, Dutch adjectives were always inflected (for frequency reasons) whereas the Papiamento adjectives were not. Alternatively, we could have created conditions in which Dutch adjectives were uninflected as well. We could also consider comparing stimuli with +/- ratings for the MLF (for both matrix languages, i.e., Papiamento and Dutch), although we would not be able to place the critical item in the same position in each condition and the experiment would be lengthy. 


\section{Conclusion}

In this study, we investigated contrasting theoretical predictions regarding conflict sites in code-switched sentences, and tried to validate, using a different bilingual population and a different language pair, previous results with Welsh-English bilinguals (see Parafita Couto et al., 2017). The main goal was to evaluate the predictions of the theoretical approaches in a laboratory setting, measuring online comprehension of code-switched utterances. Our results with Papiamento-Dutch bilinguals allow us to reject the predictions of the MLF and the MP. Given that there was no difference in responses, our results can either be interpreted as favouring Di Sciullo's prediction or, alternatively, point to a rejection of all codeswitched patterns. This is interesting, given that previous research on naturalistic production of Papiamento-Dutch code-switching showed that switching between a noun and an adjective is not as common as switching between the determiner and the Adj N complex (Parafita Couto \& Gullberg, 2017).

The state of the research to date calls for further work to be able to fully determine the theoretical and empirical implications of our findings. The present study represents the early stages of an emergent research program that warrants further inquiry. It is also a call for broadening the scope of inquiry to bridge psycholinguistic and theoretical approaches in the study of code-switching at conflict sites. Evaluating data from different approaches will force us to critically examine both our theories and our methods. For example, a recent study by StadthagenGonzález, Parafita Couto, Párraga and Damian (2017) examined adjective-noun order in Spanish-English bilinguals with two types of judgment tasks: a traditional five-point Likert scale task, and a two-alternative forced choice task which integrated a novel application of Thurstone's law of comparative judgements. Similar to the present study, they found evidence that neither the MLF nor the MP can fully account for the acceptability of Spanish-English adjective - noun switches. Instead, they found an additive effect in which both the language of the verb and the language of the adjective determine word order. They suggest that advances in our understanding of grammaticality in code-switching will be achieved by combining the insights of the two frameworks instead of considering them in isolation, or by espousing a probabilistic model of code-switching. Only after enough data and key interpretations have been collected (by studying both different and similar language pairs in different contact situations as well as different bilingualism types) will we be able to arrive at a description of the different dimensions that characterize the language faculty in its relation to code-switching. We posit that only by researching code-switching from a multi- and interdisciplinary perspective can we unveil what those specific factors are and how they modulate code-switching. 


\section{Acknowledgments}

We acknowledge the support of the University of Strathclyde (Glasgow), from which author Parafita Couto received a Researcher Development Fund to conduct this research. We would also like to thank Margaret Deuchar, Emily Fernan, Bart Jacobs, Gerrit Jan Kootstra, Guillaume Thierry, Paul Vedder, and Raiza Sattaur for their assistance at different points in the study.

\section{References}

Åfarli, T. A., Grimstad, M. B., \& Subbarao, K. V. (2013). Dakkhini and the problem of a matrix language frame in sustained language contact. International Conference on Language Contact in India. Deccan College Post Graduate and Research Institute; Pune, India.

Badiola, L., Delgado, R., Sande, A., \& Stefanich, S. (2018). Code-switching attitudes and their effects on acceptability judgment tasks. In A. Munarriz-Ibarrola, M. C. Parafita Couto \& E. Vanden Wyngaerd (Eds.), Methodologies for intra-sentential code-switching research. Linguistic Approaches to Bilingualism, 8(1), 5-24. https://doi.org/10.1075/lab.16006.bad

Blom, E., Polisenska, D., \& Weerman, F. (2008). Articles, adjectives and age of onset: the acquisition of Dutch grammatical gender. Second Language Research, 24(3), 297-331. https://doi.org/10.1177/0267658308090183

Bornkessel-Schlesewsky, I., \& Schlesewsky, M. (2009). Processing syntax and morphology: A neurocognitive perspective. Oxford: Oxford University Press.

Broekhuis, H. (2013). Syntax of Dutch. Adjectives and adjective phrases. (Comprehensive Grammar Resources). Amsterdam: Amsterdam University Press.

Cantone, K. F., \& MacSwan, J. (2009). Adjectives and word order. In L. Isurin, D. Winford \& K. de Bot (Eds.), Multidisciplinary approaches to code switching (pp. 243-278). Amsterdam: John Benjamins. https://doi.org/10.1075/sibil.41.14can

Cinque, G. (1994). On the evidence for partial N-movement in the Romance DP. In G. Cinque, J. Koster, J.-Y. Pollock, L. Rizzi \& R. Zanuttini (Eds.), Paths towards Universal Grammar. Studies in honor of Richard S. Kayne (pp. 85-110). Washington, DC: Georgetown University Press.

Cinque, G. (1999). Adverbs and functional heads. Oxford: Oxford University Press.

Cinque, G. (2005). Deriving Greenberg's universal 20 and its exceptions. Linguistic Inquiry, 36 (3), 315-332. https://doi.org/10.1162/0024389054396917

Di Sciullo, A. M. (2014). On the asymmetric nature of the operations of grammar: Evidence from codeswitching. In J. MacSwan (Ed.), Grammatical theory and bilingual codeswitching, (pp. 63-85). Cambridge: MIT Press.

Extra, G., Aarts, R., van der Avoird, T., Broeder, P., \& Yagmur, K. (2002). De andere talen van Nederland: thuis en op school. Bussum: Countinho.

Extra, G. (2013). De vitaliteit van het Papiaments in Nederland in vergelijkend perspectief. Paper presented at the Arubahuis, The Hague, 26 November 2013.

Friederici, A. D. (2002). Towards a neural basis of auditory sentence processing. Trends in Cognitive Sciences. 6, 78-84. PMID 15866191 https://doi.org/10.1006/brln.1995.1048 
Friederici, A. D., Pfeifer, E., \& Hahne, A. (1993). Event-related brain potentials during natural speech processing: Effects of semantic, morphological and syntactic violations. Brain Research, 1, 183-192.

Goilo, E. R. (1972). Papiamentu textbook. Aruba: De Wit Stores. (4th edition)

Goldrick, M., Putnam, M., \& Schwarz, L. (2016). Coactivation in bilingual grammars: A computational account of code-mixing. Bilingualism: Language and Cognition, 19(5), 857-876. https://doi.org/10.1017/S1366728915000802

Gratton, G., Coles, M. G. H., \& Donchin, E. (1983). A new method for off-line removal of ocular artifact. Electroencephalography and Clinical Neurophysiology, 55, 468-484. https://doi.org/10.1016/0013-4694(83)90135-9

Groppe, D. M., Urbach, T. P., \& Kutas, M. (2011). Mass univariate analysis of event-related brain potentials/fields I: A critical tutorial review. Psychophysiology, 48, 1711-1725. https://doi.org/10.1111/j.1469-8986.2011.01273.x

Gullberg, M., Indefrey, P., \& Muysken, P. (2009). Research techniques for the study of codeswitching. In B. E. Bullock \& A. J. Toribio (Eds.), The Cambridge handbook of linguistic code-switching (pp. 21-39). Cambridge: Cambridge University Press.

https://doi.org/10.1017/CBO9780511576331.003

Gullberg, M., \& Parafita Couto, M. (2016). An integrated perspective on code-mixing patterns beyond doubling? Bilingualism, Language and Cognition, 19(5), 885-886.

https://doi.org/10.1017/S1366728916000080

Guzzardo Tamargo, Valdés Kroff, J. R., \& Dussias, P. E. (2016). Examining the relationship between comprehension and production processes in code-switched language. Journal of Memory and Language, 89, 138-161. https://doi.org/10.1016/j.jml.2015.12.002

Hagoort, P. (2003). Interplay between syntax and semantics during sentence comprehension: ERP effects of combining syntactic and semantic violations. Journal of Cognitive Neuroscience, 15, 883-899. https://doi.org/10.1162/089892903322370807

Hahne, A., \& Friederici, A. D. (1999). Electrophysiological evidence for two steps in syntactic analysis. Early automatic and late controlled processes. Journal of Cognitive Neuroscience, 11, 194-205. https://doi.org/10.1162/089892999563328

Jacobs, B., \& Muysken, P. (in press). Heritage languages in a post-colonial setting: focus on Papiamentu. In S. Aalberse, A. Backus \& P. Muysken (Eds.) Heritage languages. An introduction. Amsterdam: Benjamins.

Jeffreys, H. (1961). Theory of probability, 3rd ed. Oxford Classic Texts in the Physical Sciences. Oxford: Oxford University Press.

Kootstra, G. J. (2015). A psycholinguistic perspective on code-switching: Lexical, structural, and socio-interactive processes. In G. Stell \& K. Yakpo. (Eds.), Code-switching between structural and sociolinguistic perspectives (pp. 39-64). Berlin: Mouton de Gruyter.

Kouwenberg, S. (2007). Papiamentu (Creole Spanish/Portuguese). In J. Holm \& P. Patrick (Eds.), Comparative creole syntax (pp. 307-332). London: Battlebridge.

Kouwenberg, S., \& Murray, E. (1994). Papiamentu. (Languages of the world/Materials, 83.) München: Lincom Europa.

López, L. (2017). Code-switching and linguistic theory. https://www.academia.edu/31206843/ Transcript_talk_at_Bilingualism_in_the_Hispanic_and_Lusophone_World

MacSwan, J. (1999). A Minimalist approach to intrasentential code switching. New York: Garland Publishing.

Mahootian, S., \& Santorini, B. (1996). Code-switching and the complement/adjunct distinction. Linguistic Inquiry, 27, 464-479. 
Maris, E., \& Oostenveld, R. (2007). Nonparametric statistical testing of EEG-and MEG-data. Journal of Neuroscience Methods, 164, 177-190. https://doi.org/10.1016/j.jneumeth.2007.03.024

Moreno, E. M., Federmeier, K. D., \& Kutas, M. (2002). Switching languages, switching palabras (words): An electrophysiological study of code switching. Brain and Language, 80, 188-207. https://doi.org/10.1006/brln.2001.2588

Morey, R. D., \& Rouder, J. N. (2015). BayesFactor: Computation of Bayes Factors for Common Designs. R package version 0.9.11-1. http://CRAN.R-project.org/package=BayesFactor

Moro, M. (2015). The universality of syntactic constraints on Spanish-English codeswitching in the USA. Language And Intercultural Communication, 15, 391-406.

https://doi.org/10.1080/14708477.2015.1015347

Munteanu, D. (1996). El Papiamento, lengua criolla hispánica. Madrid: Gredos.

Muysken, P. (2013). Language contact outcomes as the result of bilingual optimization strategies. Bilingualism: Language and Cognition, 16, 709-730.

https://doi.org/10.1017/S1366728912000727

Muysken, P., Kook, H., \& Vedder, P. (1996). Papiamento/Dutch code-switching in bilingual parent-child reading. Applied Psycholinguistics, 17, 485-505.

https://doi.org/10.1017/S0142716400008213

Myers-Scotton, C. (1993). Duelling languages: Grammatical structure in codeswitching. Oxford: Clarendon Press.

Myers-Scotton, C. (2002). Contact linguistics: Bilingual encounters and grammatical outcomes. Oxford: Oxford University Press.

https://doi.org/10.1093/acprof:oso/9780198299530.001.0001

Orgassa, A. (2009). Specific language impairment in a bilingual context: The acquisition of Dutch inflection by Turkish-Dutch learners. PhD dissertation. Amsterdam Center for Language and Communication (ACLC).

Parafita Couto, M. C., Boutonnet, B., Hoshino, N., Davies, P., Deuchar, M. \& Thierry, G. (2017). Testing alternative theoretical accounts of code-switching using event-related brain potentials: A pilot study on Welsh-English. In F. Lauchlan \& M. C. Parafita Couto (Eds.), Bilingualism and minority languages in Europe: Current trends and developments (pp. 242-256). Newcastle: Cambridge Scholars Publishing.

Parafita Couto, M. C., Davies, P., Carter, D., \& Deuchar, M. (2014). Factors affecting codeswitching. In E. Thomas \& I. Mennen (Eds.), Unraveling bilingualism: A cross-disciplinary perspective (pp. 111-140). Bristol: Multilingual Matters.

Parafita Couto, M. C., Deuchar, M., \& Fusser, M. (2015a). How do Welsh-English bilinguals deal with conflict? Adjective-noun order resolution. In G. Stell \& K. Yakpo (Eds.), Codeswitching between structural and sociolinguistic perspectives (pp. 65-84). Berlin: De Gruyter.

Parafita Couto, M. C., \& Gullberg, M. (2017). Code-switching within the noun phrase. Evidence from three corpora. International Journal of Bilingualism, 1-20.

https://doi.org/10.1177/1367006917729543

Parafita Couto, M. C., Munarriz, A., Epelde, I., Deuchar, M., \& Oyharçabal, B. (2015b). Gender conflict resolution in Basque-Spanish mixed DPs. Bilingualism: Language and Cognition, 18(2), 304-323. https://doi.org/10.1017/S136672891400011X

Polich, J. (2004). Neuropsychology of the P3a and P3b: A theoretical overview. In C. Moore \& K. Arikan (Eds.), Brainwaves and mind: Recent developments (pp. 15-29). Wheaton, IL: Kjelberg Inc. 
Polich, J. (2007). Updating P300: an integrative theory of P3a and P3b. Clinical Neurophysiology, 118(10), 2128-2148. https://doi.org/10.1016/j.clinph.2007.04.019

Santorini, B., \& Mahootian, S. (1995). Code-switching and the syntactic status of adnominal adjectives. Lingua, 95, 1-27. https://doi.org/10.1016/0024-3841(94)00026-I

Sanoudaki, E., \& Thierry, G. (2014). Juggling two grammars. In E. M. Thomas \& I. Mennen (Eds.), Advances to the study of bilingualism (pp. 214-230). Bristol, U.K.: Multilingual Matters. https://doi.org/10.21832/9781783091713-013

Schiller, N. O., \& Caramazza, A. (2003). Grammatical feature selection in noun phrase production: Evidence from German and Dutch. Journal of Memory and Language, 48, 169-194. https://doi.org/10.1016/S0749-596X(02)00508-9

Schiller, N. O., Schuhmann, T., Neyndorff, A. C., \& Jansma, B. M. (2006). The influence of semantic category membership on syntactic decisions: A study using event-related brain potentials. Brain Research, 1082(1), 153-164. https://doi.org/10.1016/j.brainres.2006.01.087

Schriefers, H. (1993). Syntactic processes in the production of noun phrases. Journal of Experimental Psychology: Learning, Memory, and Cognition, 19, 841-850.

Stadthagen-González, H., López, L., Parafita Couto, M. C., \& Párraga, A. (2018). Using twoalternative forced choice tasks and Thurstone's law of comparative judgements for codeswitching research: Examining the adjacency condition in Spanish/English code-switched sentences. In A. Munarriz-Ibarrola, M. C. Parafita Couto, \& E. Vanden Wyngaerd (Eds.), Methodologies for intra-sentential code-switching research. Linguistic Approaches to Bilingualism, 8(1), 67-97. https://doi.org/10.1075/lab.16030.sta

Stadthagen-González, H., Parafita Couto, M. C., Párraga, A., \& Damian, M. (2017). Testing alternative theoretical accounts of code-switching: Insights from comparative judgments of adjective - noun order. The International Journal of Bilingualism, 1-21.

https://doi.org/10.1177/1367006917728390

Swaab, T. Y., Ledoux, K., Camblin, C. C., \& Boudewyn, M. A. (2012). Language related ERP components. In: S. J. Luck \& E. S. Kappenman (Eds.), Oxford handbook of event-related potential components (pp. 397-440). New York: Oxford University Press.

Valdés Kroff, J. (2016). Mixed NPs in Spanish-English bilingual speech: Using a corpus based approach to inform models of sentence processing. In R. E. Guzzardo Tamargo, C. Mazak, \& M. C. Parafita Couto (Eds.), Code-switching in the Spanish-speaking Caribbean and its diaspora. Amsterdam: John Benjamins. https://doi.org/10.1075/ihll.11.12val

Valdés Kroff, J. R., Guzzardo Tamargo, R. E., \& Dussias, P. E. (2018). Experimental contributions of eye-tracking to the understanding of comprehension processes while hearing and reading code-switches. In A. Munarriz-Ibarrola, M. C. Parafita Couto, \& E. Vanden Wyngaerd (Eds.), Methodologies for intra-sentential code-switching research. Linguistic Approaches to Bilingualism, 8(1), 98-133. https://doi.org/10.1075/lab.16011.val

Valdés Kroff, J. R., Dussias, P. E., Gerfen, C., Perrotti, L., \& Bajo, M. T. (2017). Experience with code-switching modulates the use of grammatical gender during sentence processing. Linguistic Approaches to Bilingualism, 4; 7(2): 163-198.

https://doi.org/10.1075/lab.15010.val

Van Hell, J. G., Litcofsky, K. A., \& Ting, C. (2015). Sentential code-switching: cognitive and neural approaches. In J. W. Schwieter (Ed.), The Cambridge handbook of bilingual processing (pp. 459-482). Cambridge: Cambridge University Press..

https://doi.org/10.1017/CBO9781107447257.020 
Van Hell, J., Fenández, C., Koostra, G. J., Litcofsky, K., \& Ting, C. (2018). Electrophysiological and experimental-behavioral approaches to the study of intra-sentential code-switching. In A. Munarriz-Ibarrola, M. C. Parafita Couto \& E. Vanden Wyngaerd (Eds.), Methodologies for intra-sentential code-switching research. Linguistic Approaches to Bilingualism, 8:1, 134-161. https://doi.org/10.1075/lab.16010.van

Van Berkum, J. J. A. (1996). The psycholinguistics of grammatical gender: Studies in language comprehension and production. Doctoral dissertation, Max Planck Institute for Psycholinguistics. Nijmegen, Netherlands: Nijmegen University press.

\section{Address for correspondence}

M. Carmen Parafita Couto

Leiden University

Center for Linguistics

m.parafita.couto@hum.leidenuniv.nl

(D) https://orcid.org/0000-0001-7306-3393

\section{Co-author details}

Bastien Boutonnet

Leiden University

Center for Linguistics

bastien.b1@gmail.com

Niels O. Schiller

Leiden University

Center for Linguistics

N.O.Schiller@hum.leidenuniv.nl

(D) https://orcid.org/0000-0002-0392-7608

Leticia Pablos

Leiden University

Center for Linguistics

l.pablos.robles@hum.leidenuniv.nl

https://orcid.org/0000-0001-6701-7817

Marlou Perquin

Cardiff University

PerquinMN@cardiff.ac.uk

Annelies de Haan

Cardiff University

dehaanam@cardiff.ac.uk

Amy de Jong

Leiden University

Center for Linguistics

a.j.de.jong.3@umail.leidenuniv.nl

\section{Publication history}

Date received: 19 March 2017

Date accepted: 3 August 2018

Published online: 20 December 2018 